\title{
A comparative study on defluoridation capabilities of biosorbents: Isotherm, kinetics, thermodynamics, cost estimation and regeneration study
}

\author{
Endashaw Workie Yihunu', Haiyan $\mathrm{Yu}^{2}$, Wen Junhe ${ }^{2}$, \\ Zhang $\mathrm{Kai}^{1}$, Zebene Lakew Teffera ${ }^{3}$, Brhane Weldegebrial ${ }^{3}$, Ma Limin $^{{ }^{+}}$ \\ ${ }^{1}$ State Key Laboratory of Pollution Control and Resources Reuse, College of Environmental Science and Engineering, Tongji University, Shanghai \\ 200092, China \\ ${ }^{2}$ Shanghai Institute of Pollution Control and Ecological Security, Shanghai 200092, China \\ ${ }^{3}$ Department of Environment and Sustainable Development, Tongji University, Shanghai 200092, China
}

\section{ABSTRACT}

The presence of high fluoride concentration $(>1.5 \mathrm{mg} / \mathrm{L})$ in water causes serious health problems such as fluorosis, infertility, brain damage, etc., which are endemic to many places in the world. This study has investigated the fluoride removal capacity of the novel activated biochar (BTS) and hydrochar (HTS) using Teff (Eragrostis tef) straw as a precursor. Activated biochar with mesoporous structures and large specific surface area of $627.7 \mathrm{~m}^{2} / \mathrm{g}$ were prepared via pyrolysis process. Low-cost carbonaceous hydrochar were also synthesized by an acid assisted hydrothermal carbonization process. Results obtained from both adsorbents show that the best local maximum fluoride removal was achieved at $\mathrm{pH} 2$, contact time $120 \mathrm{~min}$ and agitation speed $200 \mathrm{rpm}$. The thermodynamic studies proved that the adsorption process was spontaneous and exothermic in nature. Both adsorbents equilibrium data fitted to Langmuir isotherm. However, Freundlich isotherm fitted best for BTS. The maximum fluoride loading capacity of BTS and HTS was found to be 212 and $88.7 \mathrm{mg} / \mathrm{g}$, respectively. The variation could primarily be attributed to a relatively larger Surface area for BTS. Hence, to treat fluoride contaminated water, BTS can be promising as an effective adsorbent.

Keywords: Adsorption, Biochar, Fluoride, Hydrochar, Pyrolysis, Teff (Eragrostis tef)

\section{Introduction}

Clean, safe drinking water is not easily available as it may be exposed to contamination through both natural and anthropogenic sources. Fluoride can be categorized as one of those contaminants. It is an ion of the element fluorine, a fairly common element that is widely occurring in the upper layers of the lithosphere [1]. It is often considered as a "double-edged sword" since very low levels of exposure to young children especially under the age of six may lead to stunted growth [2]. On the other hand, excessive intake leads to dental fluorosis (1.5-4.0 mg/L), skeletal fluorosis (4.0-10.0 $\mathrm{mg} / \mathrm{L}$ ) and progressive crippling scourge-skeletal fluorosis $(>10$ $\mathrm{mg} / \mathrm{L})[3,4]$. There is a safe level $(1.5 \mathrm{mg} / \mathrm{L})$ for fluoride that is essential to avoid concern and for protection of dental caries [5]
Worldwide above 200 million people from 25 nations are jeopardized by excess fluoride in drinking water exceeding the safe level [6]. This situation mostly happens in arid and semi-arid regions at which a rapid rate of chemical weathering of geological materials has occurred [7]. Due to the fact that especially in the region like East African rift valley, where all drinking water sources are naturally poisoned by fluoride, investigation of appropriate fluoride treatment techniques is mandatory.

To date, different kinds of fluoride removal techniques such as membrane process (reverse osmosis, dialysis, and electrodialysis, etc.) and adsorption have been mainly practiced [8-10]. However, some of them have long been blamed for their limitations in acceptance by the communities, especially at developing rural areas due to their after use environmental effect, high operational cost and
This is an Open Access article distributed under the terms of the Creative Commons Attribution Non-Commercial License (http://creativecommons.org/licenses/by-nc/3.0/) which permits unrestricted non-commercial use, distribution, and reproduction in any medium, provided the original work is properly cited.
Received March 11, 2019 Accepted May 24, 2019

${ }^{\dagger}$ Corresponding author

Email: lmma@tongji.edu.cn, endex.21@hotmail.com Tel: +86-13-162728386 Fax: +86-21-65986313

Copyright (C) 2020 Korean Society of Environmental Engineers 
complexity of design [11]. It is, therefore, necessary to look for the most convenient techniques depending on the location and stakeholders centred parameters [12]. Arguably, the removal of fluoride through adsorption techniques is effective due to its simplicity and expediency with high removal efficiency [13, 14]. However, the principal question in the implementation of adsorption methods is the selection of the appropriate adsorbent material (i.e., locally available, affordable, and eco-friendly).

In recent years, various indigenous biomass including agricultural wastes in the form of hydrochar, biochar, and activated carbon have been used enormously as a sustainable adsorbent for fluoride adsorption from the water. Since, they are easily available, economically feasible and biodegradable in nature $[15,16]$. Biochar is produced by incomplete combustion of plant residues, agricultural byproducts, algae and other biomasses in the absence of oxygen [17]. Biomaterials can also be widely applied for pollutant removal after their surface introduced the functional groups and carbons via a simple technical route. This process occurs under aqueous medium and relatively low temperature, referred to as hydrothermal carbonization (HTC) [18]. The presence of such functional groups with its carbonized features on the surface of hydrochar enabled it to be a promising precursor for fluoride treatment. Moreover, the suitability of both biochar and hydrochars can be improved through chemical activation via $\mathrm{HCl}$ [19], $\mathrm{ZnCl}_{2}$ [20], $\mathrm{H}_{3} \mathrm{PO}_{4}$ [21], $\mathrm{KOH}$ [22], etc., since they provide high surface area and high porosity, which are primarily responsible for effective fluoride adsorption [23]. Activation through $\mathrm{H}_{3} \mathrm{PO}_{4}$ is, however, most preferable as compared to other activation chemicals due to less hazardous after-effect on environmental safety and it also gives high adsorbent yield [24].

Several literature works have reported the adsorption of fluoride using activated biochar derived from various biomaterials such as rice husk [25], jamun leaf [26], douglas fir [27], corn stover [28], perennial grass [29], coconut fiber [30], wheat straw and pine sawdust [31]. However, the adsorption potential of fluoride via acid assisted hydrochar has not yet been reported. Furthermore, Teff (Eragrostis tef) straw has neither been synthesized as biochar nor hydrochar for this purpose.

This study has investigated the removal of fluoride via activated biochar and hydrochar prepared from Teff (Eragrostis tef) straw. To understand which adsorbent type would favorably respond to the chemical activation process, both adsorbents were chemically activated under similar activation agent $\left(\mathrm{H}_{3} \mathrm{PO}_{4}\right)$, concentration (30 wt\%) and time (3 h). Their physicochemical properties, which may attribute to the variation in adsorption behavior, are characterized. Besides, the adsorption thermodynamics, kinetic behaviors, equilibrium isotherm models and desorption studies were analyzed.

\section{Materials and Methods}

\subsection{Chemicals and Reagents}

Chemicals used such as $\mathrm{NaF}, \mathrm{H}_{3} \mathrm{PO}_{4}, \mathrm{HCl}, \mathrm{Na}_{2} \mathrm{CO}_{3}$, and $\mathrm{NaOH}$ were purchased from Sigma-Aldrich Companies. The Total Ionic Strength Adjustment Buffer (TISAB) II was purchased from Thermo scientific Orion reagent companies. All chemicals and reagents were of analytical grade and were used as received.

\subsection{Adsorbents Preparation}

Teff straw was cut into smaller pieces, washed thoroughly, dried, crushed well and sieved. Subsequently, chemical activation using phosphoric acid was done by modifying a method as demonstrated [24]. Briefly, $8 \mathrm{~g}$ of prepared Teff straw was impregnated with $56.0 \mathrm{~mL}$ of 30 wt $\% \mathrm{H}_{3} \mathrm{PO}_{4}$ solution and stirred at room temperature for $12 \mathrm{~h}$. After the supernatant was removed, the remaining wet solid precursors were directly transferred to a tubular furnace to be pyrolyzed at $450^{\circ} \mathrm{C}$ for $3 \mathrm{~h}$ under inert atmosphere $(150 \mathrm{~mL} / \mathrm{min}$ $\mathrm{N}_{2}$ ). It has been reported in literature that application of low pyrolysis temperature [32] and slow pyrolysis process [33] obtained a higher char yield having higher pore volume. The activated char was taken out after the heat was cooled to room temperature and then washed by $0.1 \mathrm{M}$ of $\mathrm{HCl}$ followed by distilled water till the effluent becomes neutral $\mathrm{pH}$. Prior to drying, about $3 \mathrm{~g}$ of it was dried purposively at different temperature, to evaluate the effect of its initial moisture content presented in sec 3.2.2 The remaining char was dried at $110^{\circ} \mathrm{C}$ for $6 \mathrm{~h}$ and then assigned as activated Teff Straw Biochar (BTS).

For hydrochar, $8 \mathrm{~g}$ of prepared Teff straw was mixed with 56.0 $\mathrm{mL}$ of $30 \mathrm{wt} \% \mathrm{H}_{3} \mathrm{PO}_{4}$ solution in a $100 \mathrm{~mL}$ Teflon lined autoclave reactor. The reactor was heated at $190^{\circ} \mathrm{C}$ for $3 \mathrm{~h}$, and then cooled naturally to room temperature. The solid product was separated by vacuum filtration, washed and dried as the procedure used for BTS. The final result was noted as activated Teff Straw Hydrochar (HTS).

\subsection{Physicochemical Characterization}

The surface morphology of both adsorbents before and after adsorption of fluoride was observed by Scanning Electron Microscope (SEM, JSM-7800F). The presence of functional groups on their surfaces was confirmed by Fourier Transform Infrared Spectroscopy (FTIR, Nicolet IS 10) in a wavelength of 400 to $4,000 \mathrm{~cm}^{-1}$. X-ray diffractometer (XRD, Bruker D8-Advance) with $\mathrm{Cu}-\mathrm{K} \alpha$ radiation $(\lambda=1.5418 \AA, 40 \mathrm{kV})$ was used to characterize the crystalline pattern of both adsorbents. The textural feature of both adsorbents was determined by $\mathrm{N}_{2}$ adsorption-desorption isotherms at $77 \mathrm{~K}$ using ASAP (Micrometrics 2460) surface area and porosity analyzer. Subsequently, the surface area and average pore size were calculated by the Brunauer-Emmett-Teller (BET) and Barret-Joyner-Halenda method, respectively. Thermogravimetric analysis was conducted on the thermal analyzer (SDT Q600) from $30^{\circ} \mathrm{C}$ to $900^{\circ} \mathrm{C}$ with a heating rate of $10^{\circ} \mathrm{C} / \mathrm{min}$ in an inert atmosphere $\left(\mathrm{N}_{2}, 100 \mathrm{~mL} / \mathrm{min}\right)$.

\subsection{Adsorption Experiment}

Sodium fluoride $(\mathrm{NaF})$ is a readily soluble inorganic compound and commonly used as a source of fluoride ion [34]. A standard fluoride solution was obtained by dissolving $0.221 \mathrm{~g}$ anhydrous $\mathrm{NaF}$ in distilled water and then diluted to the required concentration. A series of the batch experiment was done to investigate the best conditions for the adsorption parameters. Accordingly, $0.1 \mathrm{~g}$ of HTS and BTS were added separately in $20 \mathrm{mg} / \mathrm{L}$ of $100 \mathrm{~mL}$ fluoride solution with variable $\mathrm{pH}(2-12)$, agitated for $3 \mathrm{~h}$ at a $25^{\circ} \mathrm{C}$. 
Subsequently, the variation effect of contact time (15-300 min), initial adsorbent moisture content (80-20\%), initial fluoride concentration (5-100 mg/L), agitation speed (50-300 rpm) and adsorbent dose (0.1-1 g) were studied. Thermodynamic properties of the adsorbent-adsorbate reaction were evaluated at variable temperatures (288-328 K). To analyze the sorption isotherm, the experiment was employed by varying the initial fluoride concentration. The adsorption kinetics was also studied by measure the residual fluoride concentration at different adsorption time intervals. Prior to fluoride determination, the supernatant was filtered and then mixed equally with TISAB II solution to avoid the ionic interference during the fluoride measurement. The remained concentrations of fluoride were measured twice by benchtop ion meter with a fluoride ion selective electrode (PXSJ-216F, China) and the average result was used for analysis. The percentile adsorption efficiency was calculated by Eq. (1).

$$
\text { Adsorption }(\%)=\frac{C_{i}-C_{e}}{C_{0}} \times 100
$$

The amount of fluoride uptake was calculated using the mass balance equation Eq. (2):

$$
\text { Adsorption capacity }\left(Q_{e}\right)=\left(C_{i}-C_{0}\right) \frac{V}{W}
$$

where $Q_{e}(\mathrm{mg} / \mathrm{g})$ is the amount of adsorbed fluoride at equilibrium, $V$ is the volume of solution, $W$ is the weight of adsorbent (g), $C_{i}(\mathrm{mg} / \mathrm{L})$ and $C_{e}(\mathrm{mg} / \mathrm{L})$ are the initial and equilibrium fluoride concentrations $(\mathrm{mg} / \mathrm{L})$, respectively.

\subsection{Desorption Studies}

The desorption experiment was studied through separately adding $0.5 \mathrm{~g}$ of HTS and BTS to $40 \mathrm{mg} / \mathrm{L}$ of fluoride solution while other parameters remained constant. After recording the first adsorption result, the exhausted adsorbents were centrifugally separated and then soaked in $100 \mathrm{~mL}$ of $0.5 \mathrm{M} \mathrm{NaOH}$ and $\mathrm{Na}_{2} \mathrm{CO}_{3}$ solution for $12 \mathrm{~h}$ at $25^{\circ} \mathrm{C}$. Following the agitation, the mixture was again separated by centrifugation. Finally, the desorbed solids dried in the oven at $110^{\circ} \mathrm{C}$ for $12 \mathrm{~h}$. The same procedures were followed until both adsorbents' adsorption-desorption performance become under half of the original adsorbent. The desorption efficiency was calculated according to Eq. (3).

$$
\text { Desorption }(\%)=\left(\frac{C_{d e}}{C_{a d}}\right) \times 100
$$

Where $C_{d e}$ and $C_{a d}$ are desorbed and adsorbed concentrations of fluoride, respectively.

\section{Results and Discussion}

\subsection{Physicochemical Properties of the Adsorbent}

SEM images in Fig. 1 depicted the structural differences of HTS and BTS before and after adsorption. The raw BTS displayed unevenly distributed pores, rough and irregular structure while raw HTS dominantly exhibited a rough coalesced carbon layer with stacked alignment. The reason for raw BTS is due to the lignin and cellulose structures of the sample was extremely damaged and/or disappeared during pyrolysis. During the HTC process, the acidic medium has gradually seeped into the amorphous cellulose and some soluble segments of lignin of straw resulting in cracked and disrupts the cellulose chain [21]. The SEM after fluoride adsorption were observed to be a uniform morphological distribution of particles containing scattershot pores and smooth heterogeneous surfaces with dull edges in both adsorbents.

The $\mathrm{N}_{2}$ adsorption-desorption isotherms of HTS and BTS analyzed (Fig. 2). According to IUPAC classification, BTS displayed isotherm a combined type I and type IV with H4 hysteresis loop, explaining the presence of a narrow slit-like microporous and mesoporous surface gain through multilayer adsorption followed by capillary condensation.

By contrast, HTS exhibited isotherm type IV with H3 hysteresis loop, indicating staged adsorption on mesopores. Its hysteresis loop revealed loose assemblages of the plate-like structure at which the capillary condensation taking place to fill and withdraw $\mathrm{N}_{2}$ molecules on those mesopores. It is noteworthy that the BET specific surface area $\left(\mathrm{S}_{\mathrm{BET}}\right)$ and total pore volume $\left(\mathrm{V}_{\mathrm{T}}\right)$ of HTS are far less than BTS (Table S1). Hence, BTS is expected to further facilitate the adsorption of fluoride through having such favorable morphology which is accessible to adsorbate molecules in a given size and shape than HTS. The linkages of phosphate and phosphate ester with lignocellulose may encourage the expansion of the structure, whereby the voids volume was protected [22, 35]. Further, the average pore diameter $\left(\mathrm{D}_{\mathrm{av}}\right)$ shows larger for HTS than BTS.

The functionalities of both adsorbents studied by FTIR spectra are shown in Fig. 3. The peaks observed on both adsorbents at $3,421 \mathrm{~cm}^{-1}$ and $1,036 \mathrm{~cm}^{-1}$ are assigned to stretching vibrations of O-H [36] and sulfonic group, respectively. Compared to HTS, the peak observed at $2,908 \mathrm{~cm}^{-1}$ derived from the asymmetric aliphatic saturated C-H group [37] and $1,632 \mathrm{~cm}^{-1}$ indicating $\mathrm{C}=$ $\mathrm{C}$ stretching vibrations and its derived carbons [38] are not observed in BTS. Rather, BTS shows an intensity reduction of such groups due to lignin removal during the pyrolysis treatments. The bending vibration peaks of the water molecules at $1,180 \mathrm{~cm}^{-1}$ representing aromatic C-O-C stretching from cellulose. Some weak bands were also observed in both adsorbents between $700-490 \mathrm{~cm}^{-1}$, indicating the presence of C-C stretching.

Phase analysis of HTS and BTS and their XRD patterns are shown in Fig. S2. The diffraction patterns of BTS at 16.2 and $27.3^{\circ}$ shows the planes of $\mathrm{CaO}_{6} \mathrm{P}_{2}$ while $26.5^{\circ}$ shows the plane of $\mathrm{Si}\left(\mathrm{P}_{2} \mathrm{O}_{7}\right)$. Those peaks also revealed the crystalline carbonaceous structure of BTS. The sharp and intense peak at $24^{\circ}$ is due to the enlargement of crystalline size and further development of pores. The extra slight peaks appeared at 13.56, 31.35, and $42^{\circ}$ are associated with randomly existed SiC crystal structure of a short-ranged order in graphene oxide layers. The two broad peaks of HTS shown at around 14.4 and $26^{\circ}$ are signifying the amorphous $\mathrm{AlPO}_{4}$ phase [39].

The thermogravimetric curve of BTS and HTS are shown in Fig. S2. The weight loss of both adsorbents in the temperature 

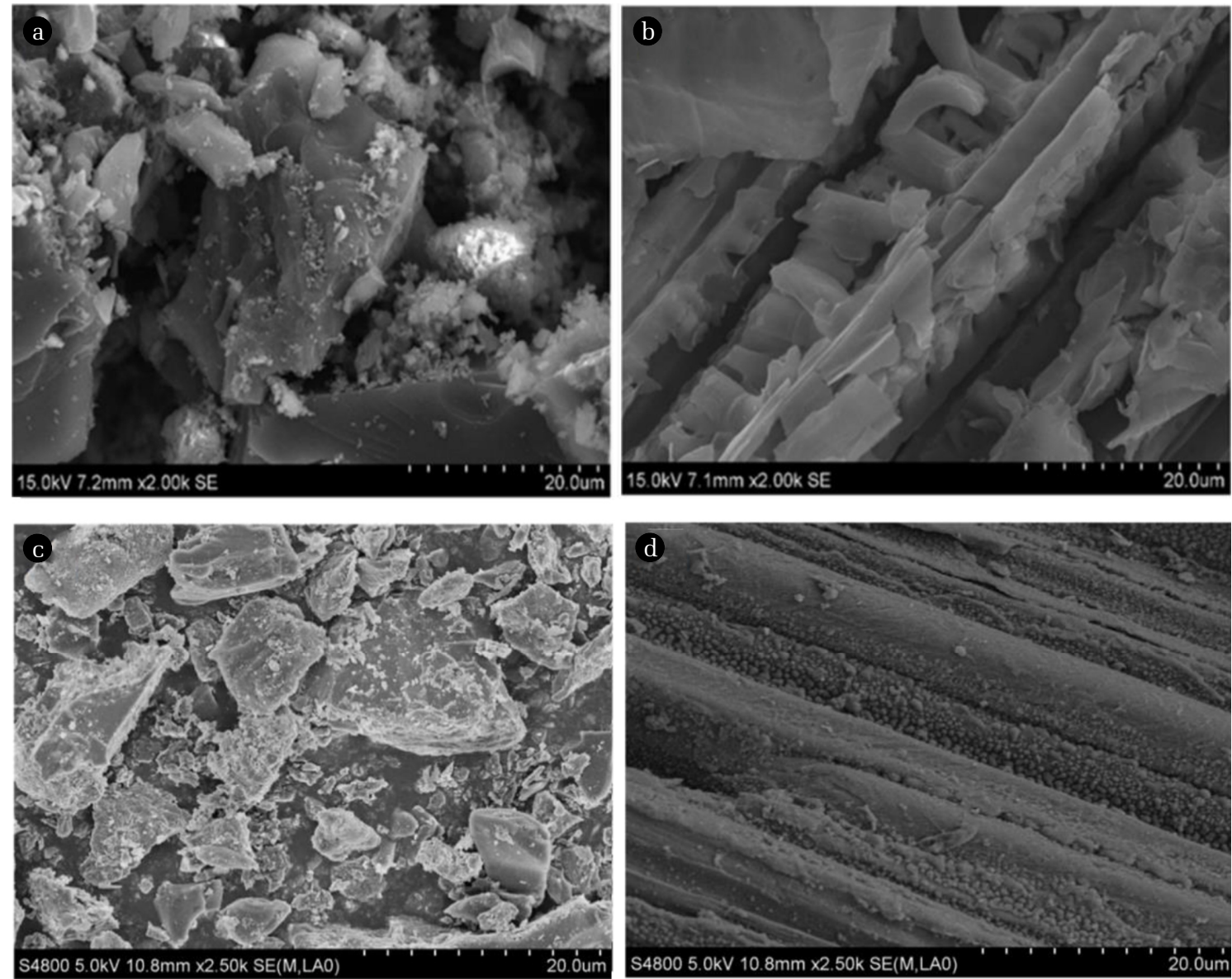

Fig. 1. SEM images of both adsorbents before (a-BTS, b-HTS) and after (c-BTS, d-HTS) adsorption.
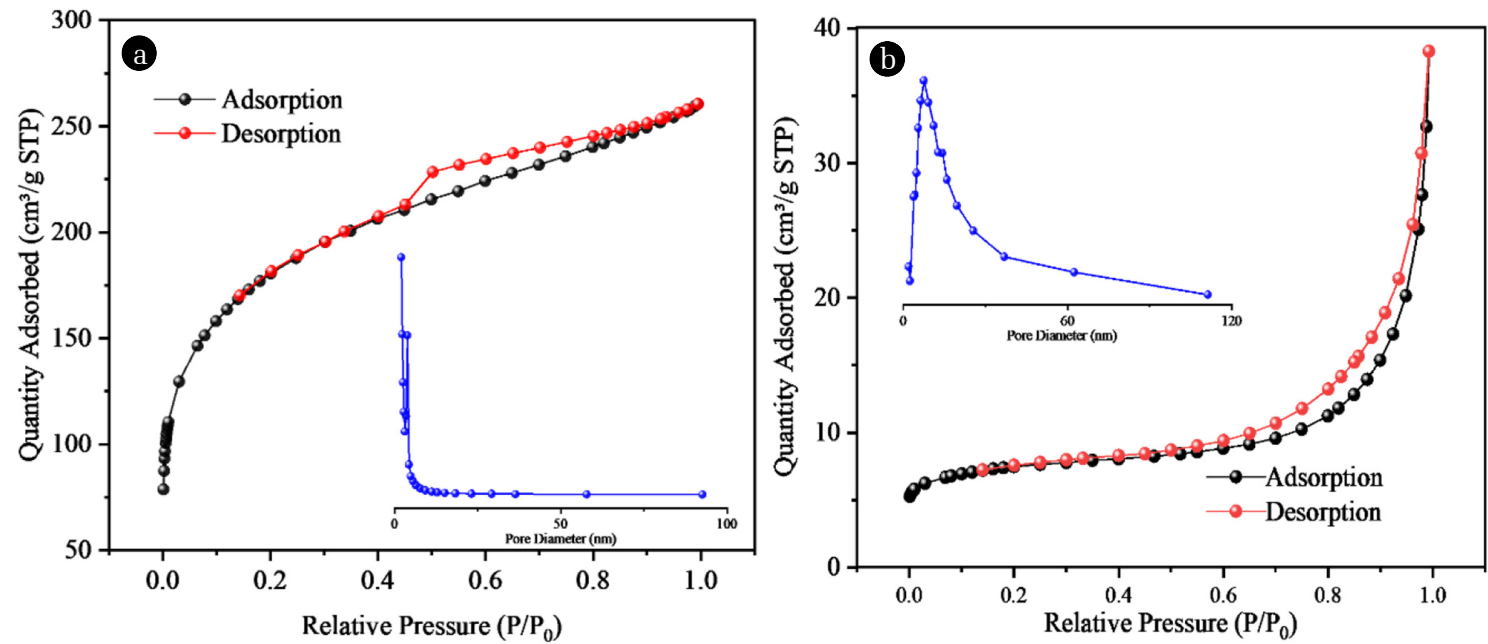

Fig. 2. The $\mathrm{N}_{2}$ adsorption-desorption isotherms of BTS (a) and HTS (b) (insert: pore size distribution).

range from 30 to $250^{\circ} \mathrm{C}$, ascribed to the surface-bound water and moisture release (dehydration). The steep and gradual weight loss (49\%) for HTS occurred from $250^{\circ} \mathrm{C}$ to $545^{\circ} \mathrm{C}$ and the major weight loss (about $76 \%$ ) for BTS took place from $250^{\circ} \mathrm{C}$ to $700^{\circ} \mathrm{C}$ is attributed mainly to the decomposition of cellulose and lignin [32]. The final weight loss (86.07\%) of BTS remained constant above $700^{\circ} \mathrm{C}$ while the total weight loss $(91.79 \%)$ for HTS remained constant after the temperature reached $545^{\circ} \mathrm{C}$. 


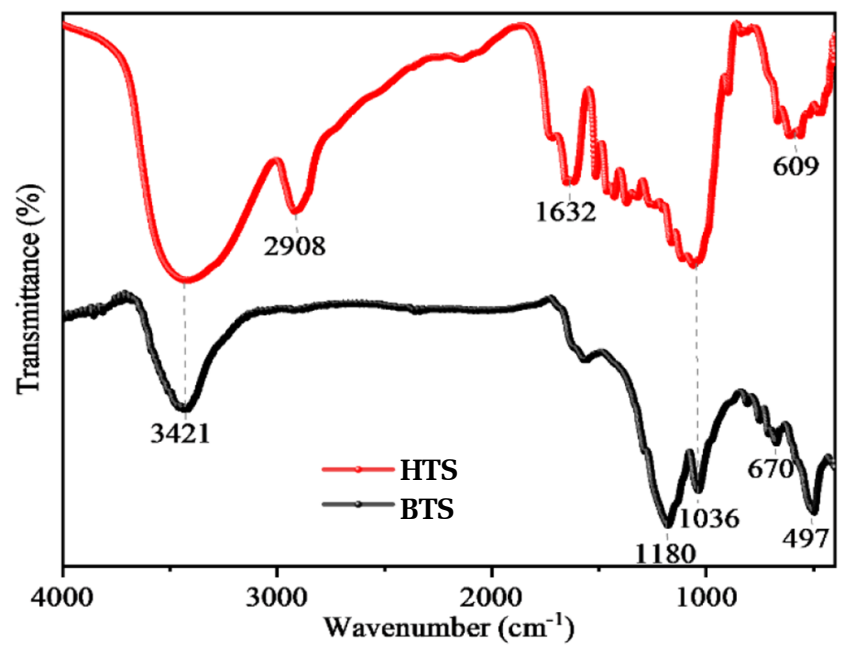

Fig. 3. FTIR spectra of BTS and HTS.

\subsection{Effects of Different Experimental Conditions}

\subsubsection{Effect of solution $\mathrm{pH}$}

The adsorption process was highly depending on the solution $\mathrm{pH}$ with a similar trend for both adsorbents. The high adsorption capacity was recorded in low $\mathrm{pH}$ with a peak at $\mathrm{pH} 2$ while abruptly ceased after pH 8 (Fig. 4(a)). It is evident that the presence of $\mathrm{H}^{+}$at low $\mathrm{pH}$, the attraction of fluoride ion with the adsorbent sites could be strengthened since the hydroxylation process is formed [40]. Conversely, the higher $\mathrm{pH}$ enhances the adsorption competition between hydroxyl and fluoride ions; thereby the adsorbent sites could be more occupied by hydroxide ions over aimed adsorbate. Hereafter, $\mathrm{pH} 2$ was used for subsequent experiments.

\subsubsection{Effect of initial adsorbent moisture}

The effect of initial moisture content present on the prepared adsorbent was studied by varying the drying temperature for both adsorbents (Fig. 4(b)). The higher adsorption capacity was shown at $15 \%$ initial moisture content. A slight decrease in adsorption capacity at the moisture level below $15 \%$ might be due to less hygroscopicity
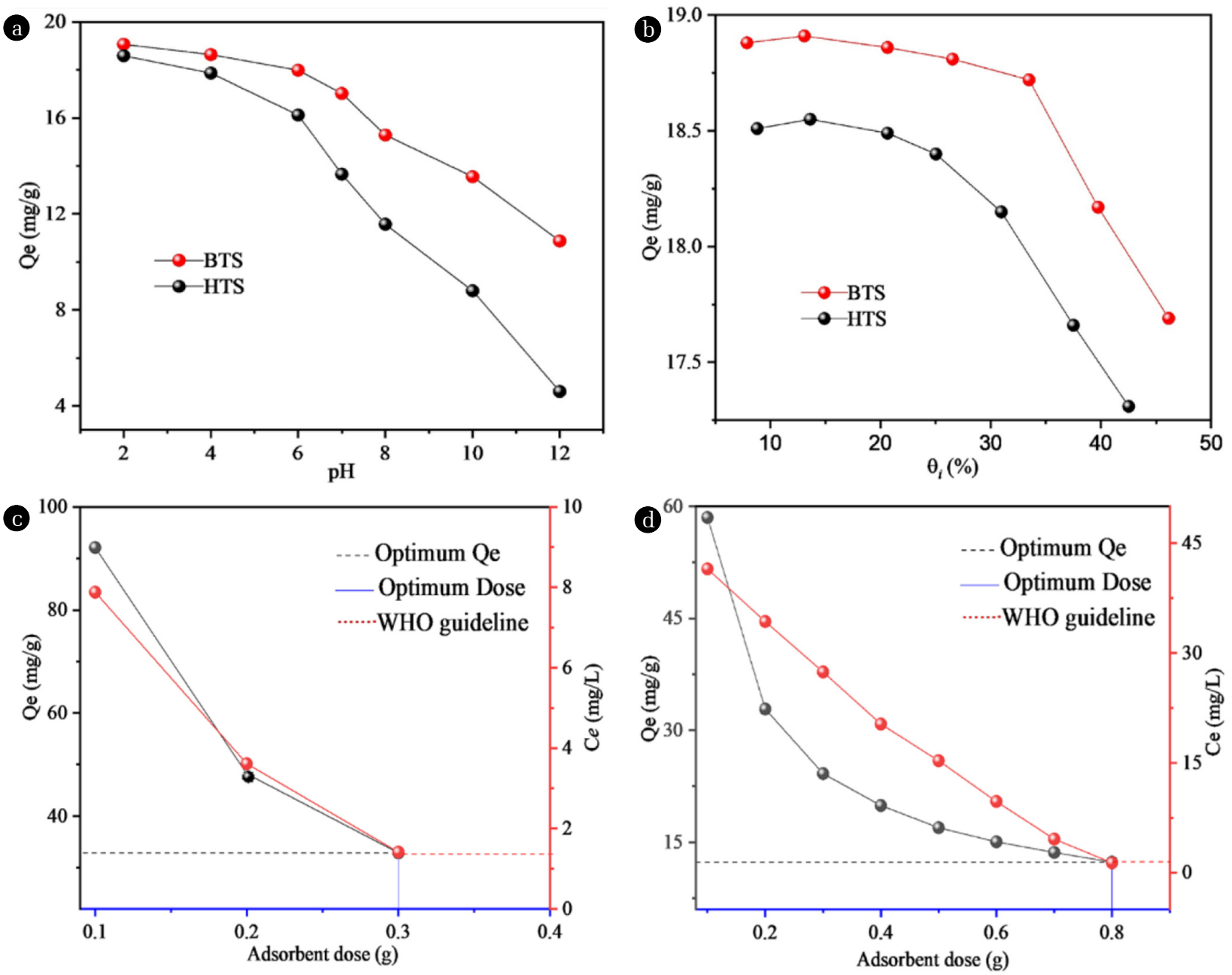

Fig. 4. Effects of $\mathrm{pH}$ (a), initial adsorbent moisture (b) and BTS dose (c) and HTS dose (d). 
at the initial adsorption stage, leads to occur slow kinetics. The adsorption capacity of both adsorbents was ceased gradually with increasing the initial moisture content. Li et al. [41] noted that the solid-liquid interaction could be inhibited through micelles (formed by the carbon-oxygen and $\mathrm{H}_{2} \mathrm{O}$ complexes on carbonaceous material), which bind the $\mathrm{H}_{2} \mathrm{O}$ molecules and then hinder the pore chamber expansion. The available adsorbent moisture content was calculated using ASTM D2867 standards [42].

\subsubsection{Effect of adsorbent dose}

In order to examine the effect of adsorbent dose, $100 \mathrm{mg} / \mathrm{L}$ of initial fluoride solution was employed with an adsorbent dose started from $0.1 \mathrm{~g}$ till the point at which the final concentration could able down to a safe level. As shown in Fig. 4(c) the amount of BTS needed to obtain safe fluoride level was achieved by using $2 / 3$ of the amount for HTS (Fig. 4(d)). This phenomenon may due to the difference in the availability of free active sites which still enabled to adsorb the remaining ions [43].

\subsubsection{Effect of contact time}

Figure S4 shows an increase in fluoride adsorption capacity with an increase in contact time until about $2 \mathrm{~h}$ for both adsorbents, after which the increment was very negligible denoting attainment of equilibrium. The instantaneous sorption reaction at the initial stage in which fluoride ions adsorbed rapidly onto the surface of the adsorbent could be due to the presence of a large number of vacant active binding sites in both adsorbents. Consequently, the driving force of mass transfer between the liquid and solid phase in an aqueous adsorption system decreasing with time elapse [44].

\subsubsection{Effect of initial fluoride concentration}

The adsorption capacity of fluoride ion was investigated at different initial fluoride concentration (Fig. S3). The adsorption capacity of BTS and HTS increased from 1.5 to $27 \mathrm{mg} / \mathrm{g}$ and 1.7 to 24 $\mathrm{mg} / \mathrm{g}$, respectively, as the initial fluoride concentration was increased from 2 to $40 \mathrm{mg} / \mathrm{L}$. At lower initial concentration, the adsorption system goes independent of initial concentration and gradually gets exhausted sharply with the increase in initial fluoride concentration [45]. This could probably take place due to an increase in the diffusion of fluoride ion to adsorption sites until sorbent saturation is achieved. Moreover, the utilization of less accessible or less active sites of the adsorbent could occur when there was more fluoride ion in the solution to be taken up.

\subsubsection{Effect of agitation speed}

The fluoride removal increased for both adsorbents on increasing the agitation speed. From Fig. S5, it can be seen that the equilibrium adsorption capacity occurred at the speed of $200 \mathrm{rpm}$ for both adsorbents. Beyond $200 \mathrm{rpm}$ agitation speed, there was no further fluoride uptake noticed for both adsorbents. The lower agitation speed leads to the accumulation of the adsorbent particles in the flask instead of spreading in the sample solution [44]. On the contrary, a higher agitation speed encourages the mobility and mass transfer of the fluoride ion in the system by reducing a boundary layer thickness around the adsorbent surface.

\subsection{Thermodynamic Studies}

The thermodynamic behavior of the adsorption process was examined through varying adsorption temperatures. The parameters result (Table S2) shows the function of temperature and related thermodynamic parameters of the adsorption which are calculated by the following equations:

$$
\begin{gathered}
K_{L}=\frac{Q_{e}}{C_{e}} \\
\triangle G^{0}=-R T \ln K_{L} \\
\ln K_{L}=\frac{\triangle S^{0}}{R}-\frac{\triangle H^{0}}{R T}
\end{gathered}
$$

Where $\Delta G^{0}(\mathrm{~kJ} / \mathrm{mol}), \Delta H^{0}(\mathrm{~kJ} / \mathrm{mol})$ and $\Delta S^{0}(\mathrm{~kJ} / \mathrm{mol} \mathrm{K})$ are the standard free energy, enthalpy and entropy change, respectively. $T$ is the temperature $(\mathrm{K})$ and $R$ is the universal gas constant (8.314 $\mathrm{J} / \mathrm{mol} \mathrm{K}$ ). The slope and intercept of the plot of the distribution coefficient $\left(\mathrm{K}_{\mathrm{L}}\right)$ versus $1 / \mathrm{T}$ were used to calculate the values $\Delta \mathrm{H}^{0}$ and $\Delta S^{0}$, respectively.

Both adsorbents exhibited almost similar thermodynamic behavior. The less negative values of $\Delta \mathrm{G}^{0}$ with increasing the adsorption temperatures showing the adsorption process was spontaneous and the exchange is proportional to the temperature for both adsorbents. The positive values of $\Delta \mathrm{H}^{0}$ revealed an exothermic adsorption process. It also likely indicated the higher electronegativity of fluoride ion and its substitution for hydroxide ion on the carbonized feature of the adsorbents, thereby chemical in nature [46]. The positive values of $\Delta S^{0}$ confirm the affinity of fluoride ions towards the adsorbents.

\subsection{Adsorption Isotherm}

The adsorption response for an increment in the amount of adsorbate at constant temperature was studied. Langmuir and Freundlich isotherm models were used as Eq. (7) and (8), respectively.

$$
\begin{gathered}
\frac{C_{e}}{Q_{e}}=\frac{C_{e}}{Q_{m}}+\frac{1}{Q_{m} K_{L}} \\
\ln Q_{e}=\ln K_{f}+\frac{1}{n_{f}} \ln C_{e}
\end{gathered}
$$

Where $Q_{e}(\mathrm{mg} / \mathrm{g})$ and $C_{0}(\mathrm{mg} / \mathrm{L})$ are the equilibrium and initial fluoride concentration, respectively; $Q_{m}$ is the maximum adsorption capacity $(\mathrm{mg} / \mathrm{g}), K_{L}(\mathrm{~L} / \mathrm{mg})$ and $K_{f}(\mathrm{~L} / \mathrm{mg})$ are the Langmuir and Freundlich constant, respectively. A plot of $\ln Q_{e}$ versus $\ln C_{e}$ is a straight line defined by a slope $n_{f}$ and intercept $\ln K_{f}$.

The result in Fig. 5 shows the Langmuir isotherm fitted with the experimental data for both adsorbents ascribing the adsorption process takes place on their surface with limited interaction of adsorbed molecules while Freundlich fitted well for BTS indicating its heterogeneous surface to perform multilayer adsorption. Table 1 describes as the maximum monolayer adsorption capacity $\mathrm{Q}_{\mathrm{m}}$ of BTS and HTS at $100 \mathrm{mg} / \mathrm{L}$ is $212 \mathrm{mg} / \mathrm{g}$ and $88.7 \mathrm{mg} / \mathrm{g}$, respectively. 


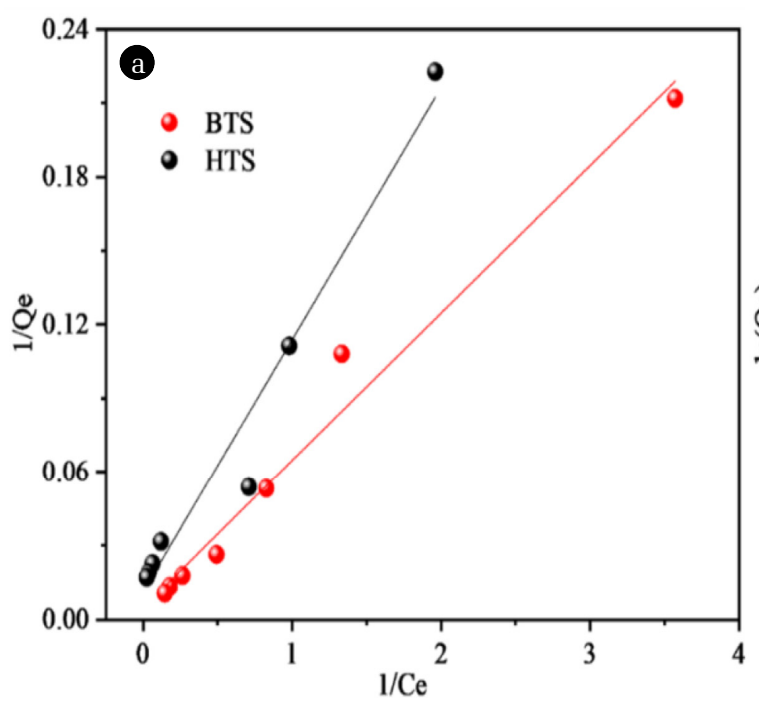

Fig. 5. The Langmuir (a) and Freundlich (b) adsorption isotherms.

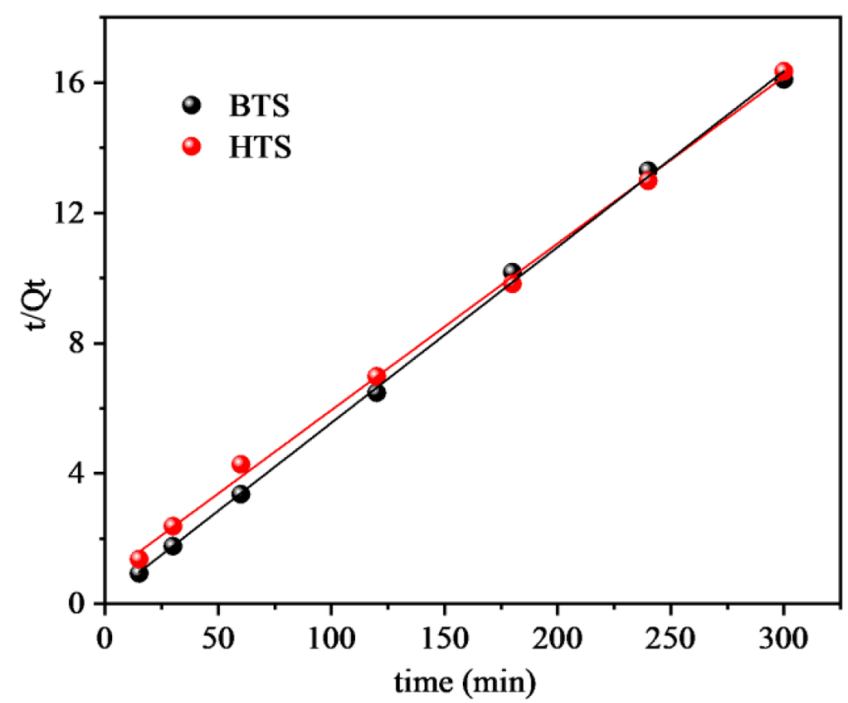

Fig. 6. The pseudo-second-order kinetics fitting.

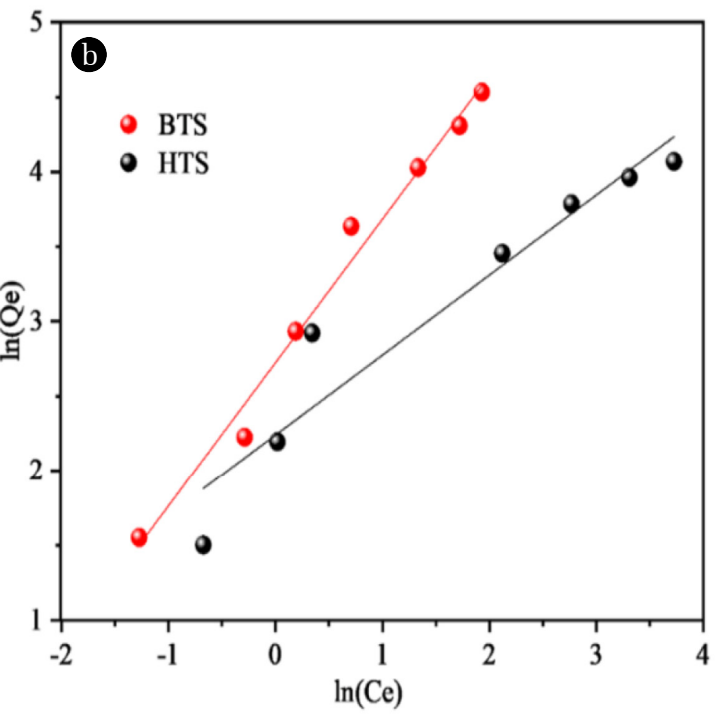

3.5. Adsorption Kinetics

The adsorption kinetic behaviour of fluoride on to BTS and HTS were analysed. The experimental data were correlated by using the pseudo-first-order and pseudo-second-order kinetic models. The pseudo-first order model equation is:

$$
\ln \left(Q_{e}-Q_{t}\right)=\ln Q_{e}-k_{1} t
$$

And the pseudo-second-order model equation:

$$
\frac{t}{Q_{t}}=\frac{1}{k_{2} Q_{e}^{2}}+\frac{1}{Q_{e}} t
$$

Where $Q_{e}(\mathrm{mg} / \mathrm{g})$ and $Q_{t}(\mathrm{mg} / \mathrm{g})$ are the adsorbed amount of fluoride at equilibrium and at a time $t$, respectively; $k_{1}$ and $k_{2}$ are the $(1 / \mathrm{min})$ and rate constant (g/mg. min), respectively.

Based on the higher correlation coefficients along with a close value of experimental and calculated adsorption capacity(Table 2), the pseudo-second-order was favorably fitted by the pseudo-sec-

\begin{tabular}{|c|c|c|c|c|c|c|}
\hline \multirow{2}{*}{ Adsorbents } & \multicolumn{3}{|c|}{ Langmui models } & \multicolumn{3}{|c|}{ Freundlich models } \\
\hline & $q_{m(m g / g)}$ & $\boldsymbol{K}_{L}(L / m g)$ & $\mathbf{R}^{2}$ & $\boldsymbol{K}_{f}(m g / g)$ & $\mathbf{N}$ & $\mathbf{R}^{2}$ \\
\hline BTS & 212 & 0.078 & 0.970 & 6.6 & 1.04 & 0.98 \\
\hline HTS & 88.7 & 0.12 & 0.963 & 4.7 & 1.86 & 0.91 \\
\hline
\end{tabular}

Table 1. Langmuir and Freundlich Isotherm Parameters Obtained from Adsorption of on BTS and HTS

\begin{tabular}{|c|c|c|c|c|c|c|}
\hline \multirow{2}{*}{ Adsorbents } & \multicolumn{3}{|c|}{ Pseudo-first-order } & \multicolumn{3}{|c|}{ Pseudo-second-order } \\
\hline & $K_{1}(1 / \min )$ & $q_{e}(m g / g)$ & $\mathbf{R}^{2}$ & $K_{2}(g / m g \min ) \times 10^{-2}$ & $q_{e}(m g / g)$ & $\mathbf{R}^{2}$ \\
\hline BTS & 0.05 & 2.05 & 0.94 & 1.88 & 18.8 & 0.999 \\
\hline HTS & 0.06 & 3.02 & 0.97 & 1.21 & 18.6 & 0.998 \\
\hline
\end{tabular}

Table 2. Pseudo-First-Order and Pseudo-Second-Order Kinetic Parameters for the Adsorption of Fluoride on to BTS and HTS 
ond-order model than the pseudo-first-order (Fig. 6). Thus, the adsorption of fluoride onto both adsorbents was governed by a chemical reaction at which the electrons are shared between adsorbent sites and fluoride ions via valency forces.

\subsection{Desorption Studies}

The desorption potential of fluoride ion from the exhausted adsorbent was directly proportional with the eluent concentration. The maximum desorption capacity of BTS and HTS using $\mathrm{NaOH}$ was found to be $75 \%$ and $84 \%$, respectively. By contrast, higher desorption was performed by using $\mathrm{Na}_{2} \mathrm{CO}_{3}$ with $82 \%$ for HTS and $91 \%$ for BTS. In general, HTS has better desorption efficiency than BTS. This may be due to less affinity of fluoride ion with HTS surface.

\subsection{Cost Analysis}

Considering the raw materials and oven cost is free since the oven heat can be replaced by sunlight, the remaining cost mainly for activation chemicals (i.e., phosphoric acid) and electric power was calculated. The total cost spent to produce $1 \mathrm{~kg}$ of BTS and 1 $\mathrm{kg}$ HTS on lab scale is $\$ 3.80$ and $\$ 5.5$, respectively. However, this cost would be lower when it will be produced commercially on a large pilot scale.

\section{Conclusions}

This paper presents the preparation, comparative characterization and fluoride removal performance of activated BTS and HTS. Both adsorbents produced under minimum activation condition (low $\mathrm{H}_{3} \mathrm{PO}_{4}$ concentration and temperature) except at nearly long activation time. Pyrolysis process could produce a porous adsorbent as compared to the HTC process. The SEM analysis indicated that the surface morphology of both adsorbents was different prior to and after fluoride adsorption. The FTIR study revealed the presence of more functional groups on the surface of HTS. The BTS performed a multistage decomposition with relatively stable intermediates, indicates the temperature limit of stability of reactants and intermediate products. The $\mathrm{pH}$ of the solution and the amount of adsorbent significantly affected the adsorption process. The result indicated that an increase in initial fluoride concentration had a positive effect on adsorption capacity for a given mass of adsorbent. Langmuir isotherm was fitted both adsorbents equilibrium data and Freundlich isotherm fitted well BTS. The adsorption kinetics fitted pseudo-second-order for both adsorbents, indicating the chemisorption process. The maximum fluoride adsorption capacity of BTS was far greater than HTS. The cost spent on preparation of HTS is cheaper as compared for BTS. The characterization, adsorption experiment, kinetics, and isotherm studies are indicated BTS as an efficient adsorbent for fluoride contaminated water.

\section{Acknowledgments}

This work was supported by the Key Program of China (2018YFC1803103, 2017ZX07206) and National Natural Science Foundation of China (No. 21377098).

\section{Nomenclature}

$\begin{array}{ll}\alpha & \text { Alpha } \\ \lambda & \text { Lambda } \\ \Delta & \text { Delta } \\ \mathrm{W}_{\mathrm{t}} & \text { Weight } \\ \mathrm{C}_{\mathrm{i}} & \text { Initial concentration } \\ \mathrm{kV} & \text { kilovolt } \\ \mathrm{R}^{2} & \text { Regression } \\ \mathrm{Q}_{\mathrm{e}} & \text { Equilibrium adsorption capacity (mg/g) } \\ \mathrm{Q}_{\mathrm{m}} & \text { Maximum adsorption capacity (mg/g) }\end{array}$

\section{References}

1. Peckham S, Awofeso N. Water fluoridation: A critical review of the physiological effects of ingested fluoride as a public health intervention. Sci. World J. 2014;293019.

2. Wang S, Wang Z, Cheng X, et al. Arsenic and fluoride exposure in drinking water: Children's IQ and growth in Shanyin County, Shanxi Province, China. Environ. Health Perspect. 2007;115:643-647.

3. Ganvir V, Das K. Removal of fluoride from drinking water using aluminum hydroxide coated rice husk ash. J. Hazard. Mater. 2011;185:1287-1294.

4. Nair VV, Aravind A, Varghese DK. Defluoridation of water by composite bed of low-cost bio-adsorbents. Int. J. Adv. Technol. Eng. Sci. 2016;4:122-131.

5. WHO. Guidelines for drinking-water quality. 4th ed. WHO Library cataloguing-in-Publication Data; 2011.

6. Edmunds WM, Smedley PL. Fluoride in natural waters. In: Selinus O, ed. Essentials of medical geology. Dordrecht: Springer; 2013. p. 311-336.

7. Kravchenko J, Rango T, Akushevich I, et al. The effect of non-fluoride factors on risk of dental fluorosis: Evidence from rural populations of the Main Ethiopian Rift. Sci. Total Environ. 2014;488-489:595-606.

8. Singh J, Singh P, Singh A. Fluoride ions vs removal technologies: A study. Arab. J. Chem. 2016;9:815-824.

9. Waghmare SS, Arfin T. Fluoride removal from water by various techniques. Int. J. Innov. Sci. Eng. Technol. 2015;2:560-571.

10. Bagastyo AY, Anggrainy AD, Nindita CS, Warmadewanthi. Electrodialytic removal of fluoride and calcium ions to recover phosphate from fertilizer industry wastewater. Sustain. Environ. Res. 2017;27:230-237.

11. Brunson LR, Sabatini DA. Practical considerations, column studies and natural organic material competition for fluoride removal with bone char and aluminum amended materials in the Main Ethiopian Rift Valley. Sci. Total Environ. 2014;488-489:580-587.

12. Osterwalder L, Johnson CA, Yang H, Johnston RB. Multi-criteria assessment of community-based fluoride-removal technologies for rural Ethiopia. Sci. Total Environ. 2014;488-489:532-538.

13. Yadav KK, Gupta N, Kumar V, Khan SA, Kumar A. A review of emerging adsorbents and current demand for defluoridation of water: Bright future in water sustainability. Environ. Int. 2018;111:80-108.

14. Goswami P, Sharma A, Sharma S, Verma S. Defluoridation 
of water using low cost adsorbent. Int. J. Chem. Stud. 2015;3:109-112.

15. Bhatnagar A, Kumar E, Sillanpää M. Fluoride removal from water by adsorption - A review. Chem. Eng. J. 2011;171:811-840.

16. Harikumar PSP, Jaseela C, Megha T. Defluoridation of water using biosorbents. Nat. Sci. 2012;4:245-251.

17. Jain A, Balasubramanian R, Srinivasan MP. Hydrothermal conversion of biomass waste to activated carbon with high porosity: A review. Chem. Eng. J. 2016;283:789-805.

18. Xu Q, Qian Q, Quek A, Ning A, Zeng G, Wang J. Hydrothermal carbonization of macroalgae and the effects of experimental parameters on the properties of hydrochars. ACS Sustain. Chem. Eng. 2013;1:1092-1101.

19. Qian WC, Luo XP, Wang X, Guo M, Li B. Removal of methylene blue from aqueous solution by modified bamboo hydrochar. Ecotoxicol. Environ. Saf. 2018;157:300-306.

20. Zhang H, Yan Y, Yang L. Preparation of activated carbon from sawdust by zinc chloride activation. Adsorption 2010;16:161-166.

21. Lei Y, Su H, Tian F. A novel nitrogen enriched hydrochar adsorbents derived from salix biomass for $\mathrm{Cr}(\mathrm{VI})$ adsorption. Sci. Rep. 2018;8:1-9.

22. Tran HN, Lee CK, Nguyen TV, Chao HP. Saccharide-derived microporous spherical biochar prepared from hydrothermal carbonization and different pyrolysis temperatures: Synthesis, characterization, and application in water treatment. Environ. Technol. 2018;39:2747-2760.

23. Jain A, Xu C, Jayaraman S, Balasubramanian R, Lee JY, Srinivasan MP. Mesoporous activated carbons with enhanced porosity by optimal hydrothermal pre-treatment of biomass for supercapacitor applications. Microporous Mesoporous Mater. 2015;218:55-61.

24. Yakout SM, Sharaf El-Deen G. Characterization of activated carbon prepared by phosphoric acid activation of olive stones. Arab. J. Chem. 2016;9:S1155-S1162.

25. Goswami R, Kumar M. Removal of fluoride from aqueous solution using nanoscale rice husk biochar. Groundw. Sustain. Dev. 2018;7:446-451.

26. Tirkey P, Bhattacharya T, Chakraborty S. Optimization of fluoride removal from aqueous solution using Jamun (Syzygium cumini) leaf ash. Process Saf. Environ. Prot. 2018;115:125-138.

27. Bombuwala Dewage N, Liyanage AS, Pittman CU Jr, Mohan D, Mlsna T. Fast nitrate and fluoride adsorption and magnetic separation from water on $\alpha-\mathrm{Fe}_{2} \mathrm{O}_{3}$ and $\mathrm{Fe}_{3} \mathrm{O}_{4}$ dispersed on Douglas fir biochar. Bioresour. Technol. 2018;263:258-265.

28. Dinesh M, Sandeep K, Anju S. Fluoride removal from ground water using magnetic and nonmagnetic corn stover biochars. Ecol. Eng. 2014;73:798-808.

29. Saikia R, Goswami R, Bordoloi N, et al. Removal of arsenic and fluoride from aqueous solution by biomass based activated biochar: Optimization through response surface methodology. J. Environ. Chem. Eng. 2015;6:5528-5539.

30. Mondal NK, Bhaumik R, Datta JK. Removal of fluoride by aluminum impregnated coconut fiber from synthetic fluoride solution and natural water. Alexandria Eng. J. 2015;54:1273-1284.

31. Kumar Yadav A, Abbassi R, Gupta A, Dadashzadeh M. Removal of fluoride from aqueous solution and groundwater by wheat straw, sawdust and activated bagasse carbon of sugarcane. Ecol. Eng. 2013;52:211-218.

32. Chowdhury ZZ, Karim MZ, Ashraf MA, Khalid K. Influence of carbonization temperature on physicochemical properties of biochar derived from. BioResources 2016;11:3356-3372.

33. Üner O, Bayrak Y. The effect of carbonization temperature, carbonization time and impregnation ratio on the properties of activated carbon produced from Arundo donax. Microporous Mesoporous Mater. 2018;268:225-234.

34. Halpern DF. Sodium fluoride. In: Encyclopedia of reagents for organic synthesis. Chichester, UK: John Wiley \& Sons, Ltd.; 2001.

35. Kundu A, Sen Gupta B, Hashim MA, Redzwan G. Taguchi optimization approach for production of activated carbon from phosphoric acid impregnated palm kernel shell by microwave heating. J. Clean. Prod. 2015;105:420-427.

36. Hongtao L, Shuxia L, Hua Z, et al. Comparative study on synchronous adsorption of arsenate and fluoride in aqueous solution onto MgAlFe-LDHs with different intercalating anions. RSC Adv. 2018;58:33301-33313.

37. Heilmann SM, Ted Davis H, Jader LR, et al. Hydrothermal carbonization of microalgae. Biomass Bioenerg. 2010;34:875-882.

38. Sano H, Omine K, Prabhakaran M, Darchen A, Sivasankar V. Groundwater fluoride removal using modified mesoporous dung carbon and the impact of hydrogen-carbonate in borehole samples. Ecotoxicol. Environ. Saf. 2018;165:232-242.

39. Graetsch HA. Thermal expansion and thermally induced variations of the crystal structure of $\mathrm{AlPO}_{4}$ low cristobalite. Neues Jb. Miner. Monat. 2003;2003:289-301.

40. Gebrewold BD, Kijjanapanich P, Rene ER, Lens PNL, Annachhatre AP. Fluoride removal from groundwater using chemically modified rice husk and corn cob activated carbon. Environ. Technol. 2018:1-15.

41. Li YH, Lee C, Gullett B. The effect of activated carbon surface moisture on low temperature mercury adsorption. Carbon 2002;40:65-72.

42. ASTM D2867. Standarad test methods for moisture in activated carbon. In: ASTM International 10.1520/DR; West Conshohocken (PA): ASTM International; 2009.

43. Mehta D, Mondal P, George S. Utilization of marble waste powder as a novel adsorbent for removal of fluoride ions from aqueous solution. 2016;4:932-942.

44. Bhaumik R, Mondal NK. Optimizing adsorption of fluoride from water by modified banana peel dust using response surface modelling approach. Appl. Water Sci. 2016;6:115-135.

45. Raji F, Pakizeh M. Study of $\mathrm{Hg}$ (II) species removal from aqueous solution using hybrid ZnCl 2-MCM-41 adsorbent. Appl. Surf. Sci. 2012;282:415-424.

46. Pongener C, Bhomick PC, Supong A, Baruah M, Sinha BU, Sinha D. Adsorption of fluoride onto activated carbon synthesized from Manihot esculenta biomass - Equilibrium, kinetic and thermodynamic studies. J. Environ. Chem. Eng. 2018;6: 2382-2389. 